\title{
Optimizing slow pyrolysis of banana peels wastes using response surface methodology
}

\author{
Godfrey Omulo ${ }^{1,2^{\dagger}}$, Noble Banadda ${ }^{1}$, Isa Kabenge ${ }^{1}$, Jeffrey Seay ${ }^{3}$ \\ ${ }^{1}$ Department of Agricultural and Biosystems Engineering, Makerere University, Kampala, Uganda \\ ${ }^{2}$ Institute of Agricultural Sciences in the Tropics (Hans-Ruthenberg-Institute), Universität Hohenheim (490), 70593 Stuttgart, Germany \\ ${ }^{3}$ Department of Chemical and Materials Engineering, University of Kentucky, Paducah, KY, USA
}

\begin{abstract}
Renewable energy from biomass and biodegradable wastes can significantly supplement the global energy demand if properly harnessed. Pyrolysis is the most profound modern technique that has proved effective and efficient in the energy conversion of biomass to yield various products like bio-oil, biochar, and syngas. This study focuses on optimization of slow pyrolysis of banana peels waste to yield banana peels vinegar, tar and biochar as bio-infrastructure products. Response surface methodology using central composite design was used to determine the optimum conditions for the banana wastes using a batch reactor pyrolysis system. Three factors namely heating temperature $\left(350-550^{\circ} \mathrm{C}\right)$, sample mass $(200-800 \mathrm{~g})$ and residence time $(45-90 \mathrm{~min})$ were varied with a total of 20 individual experiments. The optimal conditions for wood vinegar yield $(48.01 \%)$ were $362.6^{\circ} \mathrm{C}, 989.9 \mathrm{~g}$ and $104.2 \mathrm{~min}$ for peels and biochar yield $(30.10 \%)$ were $585.9^{\circ} \mathrm{C}, 989.9 \mathrm{~g}$ and $104.2 \mathrm{~min}$. The slow pyrolysis showed significant energy conversion efficiencies of about $90 \%$ at $p$-value $\leq 0.05$. These research findings are of primary importance to Uganda considering the abundant banana wastes amounting to 17.5 million tonnes generated annually, thus using them as pyrolysis feedstock can boost the country's energy status.
\end{abstract}

Keywords: Biochar, Optimization, Renewable energy, Response surface methodology, Wood vinegar

\section{Introduction}

The quick deterioration in the amount of fossil fuel yields all over the world due to the depletion of the available reserve and the exorbitant technologies applied to generate them underscores the need for adoption of renewable energies as a supplement option [1-3]. Similarly, the world energy demand is on the rise due to the steady population increase and the technological advancements which have facilitated an increase in energy utilization habits across the world [4]. Consequently, the production of renewable energy resources such as bio-fuel is useful in subsidizing the current fossil-derived fuels like coal, natural gas and petroleum and lead to sustainable economic growth [5]. For developing countries, harnessing biomaterials to produce renewable energies like bio-oil and biochar is a particularly feasible idea considering that they are cheap and economically and environmentally viable [3, 6]. According to Fan et al. [7] there are two leading indicators

This is an Open Access article distributed under the terms of the Creative Commons Attribution Non-Commercial License (http://creativecommons.org/licenses/by-nc/3.0/) which permits unrestricted non-commercial use, distribution, and reproduction in any medium, provided the original work is properly cited.

Copyright (C) 2019 Korean Society of Environmental Engineers that should propel the world's interest towards maximum utilization of renewable energy: the increased negative environmental effects like greenhouse emissions resulting from the fossil fuels and the imminent uncertainty of the fossils fuels that are in a decreasing trend.

Therefore, pyrolysis, the process of thermochemical decomposition of biomass in the absence of oxygen at high temperatures $\left(350-700^{\circ} \mathrm{C}\right)$ has proved feasible though with minimal challenges $[8,9]$. Depending on factors such as heating temperature range, type of biomass fed, the retention time, particle size among others, different pyrolysis yields are attained. According to Demirbas [10] and Cantrell et al. [11], slow pyrolysis is achieved at a low heating temperature of $400^{\circ} \mathrm{C}$ and a long solids residence time causing the secondary cracking of the primary products. In slow pyrolysis biochar yields are higher (up to 45\%) compared to bio-oil $(30 \%)[8,12]$. This is due to the lower heating rates and longer retention time that enable vapors formed from complete secondary reactions to be eliminated thus forming the carbonaceous solid
Received August 2, 2018 Accepted September 15, 2018
${ }^{\dagger}$ Corresponding author
Email: omuloh@gmail.com
Tel: +254-723-215-608
ORCID: 0000-0002-2501-3487 
biochar [13]. Slow pyrolysis has in the recent past received great attention in utilizing lignocellulosic biomasses into bio-oils, biochar, and non-condensable gases. It has been used to pyrolyse varied biomass feedstocks like microalgae, eucalyptus, castor meal, coconut pericarp, sugarcane bagasse, water hyacinth, cotton stalk, hazelnut shells, sunflower, Euphorbia rigida, rice straw, sorghum, switchgrass and corn stalks among others [4, 14-17].

Uganda is rich in biomasses that can be used as feedstock for pyrolysis systems. Ranging from natural forest residues to agricultural wastes, industrial wastes, sewage sludge as well as municipal wastes, the country has a high potential of generating enormous amounts of biofuels. One of the principal food crops grown in Uganda is banana which occupies approximately $17 \%$ of the country's total agricultural land (9, 115, $180 \mathrm{ha}$ ) [18]. According to Fernandes et al. [19], for every single tonne of bananas harvested an average of four tonnes of lignocellulosic wastes including three tons pseudostem, $480 \mathrm{~kg}$ leaves, $440 \mathrm{~kg}$ banana peels and $160 \mathrm{~kg}$ stalks as well as $100 \mathrm{~kg}$ of rotten fruits result. This translates to about 17,500,000 tonnes of banana wastes annually in Uganda [18]. Currently, these wastes are mostly spread over the fields and left to decompose with time. Similarly, only small amounts of the banana fruit peels are utilized as animal feeds by farmers as well as biogas digestion feedstock especially for experimental purposes [20]. Therefore, the banana wastes have contributed greatly to environmental pollution and soil degradation since no proper utilization and value addition has been employed.

In this research banana peel wastes were used as feedstocks for slow pyrolysis and the operating conditions were optimized using Minitab 16 software [21]. Therefore, the aim of this research was to optimize the slow pyrolysis of banana peel waste using response surface methodology (RSM). Minitab 16 software was used to develop the central composite design (CCD) experimental design and to investigate the optimum conditions. The statistical interactions various variables including heating temperature, sample mass and retention time in response to vinegar, tar and biochar yields were investigated. The yields of the banana biomass wastes products significantly depended on mass fed and heating temperature unlike on the retention time.

\section{Materials and Methods}

\subsection{Materials}

This project was conducted at Makerere University Agricultural Research Institute Kabanyolo (MUARIK) agricultural engineering workshop, Uganda. The institute is situated in Wakiso district at latitude $0.4500^{\circ}$ and longitude $32.6167^{\circ}$. Wet banana peels utilized were randomly harnessed from the students' canteen kitchen. The samples were initially prepared by cutting into small pieces and thoroughly washing them before being oven dried at $100^{\circ} \mathrm{C}$ for $24 \mathrm{~h}$ to a moisture content of $5-6 \%$ [6].

\subsection{Sample Analysis}

Proximate analysis of the banana peels samples' moisture, volatile matter, fixed carbon and ash contents were determined using the oven and muffle furnace ashing methods. The lignocellulosic analysis to determine the cellulose, hemicellulose and lignin fractions of the banana biomass samples were carried out by the Van-Soest and Wine methodology and procedures [22-24]. The ultimate analysis for carbon, hydrogen and sulfur contents were done using ULTRA CHS-580 elemental analyzer while the nitrogen content was determined by the calorimetric method. The percentage of oxygen was calculated as the difference. The calorimetric experiment was carried out using a bomb calorimeter (Ika 2000 Basic Model) according to DIN 51900 steps [25] while the thermo-gravimetric analysis was done using the Eltra Thermostat TGA 1.4.2.12 model according to ASTM D5142 procedure [26]. The proximate and elemental analyses values for the dried banana peels samples are illustrated in Table 1.

\subsection{Experimental Setup}

This pyrolysis process for the banana peels wastes was done using a batch reactor. The dimensions of the steel cylindrical reactor were $355 \mathrm{~mm}$ internal diameter and a height of $380 \mathrm{~mm}$. The reactor was heated indirectly to high temperatures using a rocket stove designed with two openings for wood fuel and combustion air and insulated with vermiculites to prevent heat loss (Fig. S1) [27]. The stove was fitted with a tight lid to prevent vapor and heat loss and to channel smoke through the chimney. The reactor had three openings for fitting the thermocouple for measuring the temperature, pressure relief valve connection and channelling the hot vapor to condensation points. There were two stages of condensation for the heavy gases and the less dense gases while the non-condensable gases were channelled through a pipe and collected separately. The fuel source for heating the reactor was dry firewood heated at a constant average rate of $10^{\circ} \mathrm{C} / \mathrm{min}$.

The dried pieces of banana peel biomass feedstock were weighed on an electronic scale between 200-800 g before being fed into the reactor. The reactor was then closed with an airtight lid before being put into the rocket stove. The experiment set up lacked a provision for flushing nitrogen gas through the reactor

Table 1. Proximate and Elemental Analyses for Banana Peels Wastes

\begin{tabular}{ccccccc}
\hline Proximate analysis & Moisture content & Volatile Matter content & Fixed Carbon content & \multicolumn{2}{c}{ Ash content } \\
\hline Peels wt. $\%$ & $11.56^{\mathrm{a}} \pm 0.06$ & $88.02^{\mathrm{a}} \pm 1.33$ & $2.70^{\mathrm{a}} \pm 0.78$ & $9.28^{\mathrm{a}} \pm 0.22$ & ${ }^{2}$ \\
\hline Elemental analysis & Carbon & Hydrogen & Nitrogen & ${ }^{*}$ Oxygen & Sulphur \\
\hline Peels wt. $\%$ & $35.65^{\mathrm{a}} \pm 0.21$ & $6.19^{\mathrm{a}} \pm 0.07$ & $1.94^{\mathrm{a}} \pm 0.16$ & $45.94^{\mathrm{a}} \pm 0.17$ & $20.75^{\mathrm{a}} \pm 9.55 \mathrm{ppm}$ \\
\hline
\end{tabular}

${ }^{*}$ Oxygen was calculated by difference $=100-($ Carbon + Hydrogen + Nitrogen $)$

${ }^{a}$ Means not labeled with letter (a) are significantly different from control level mean 

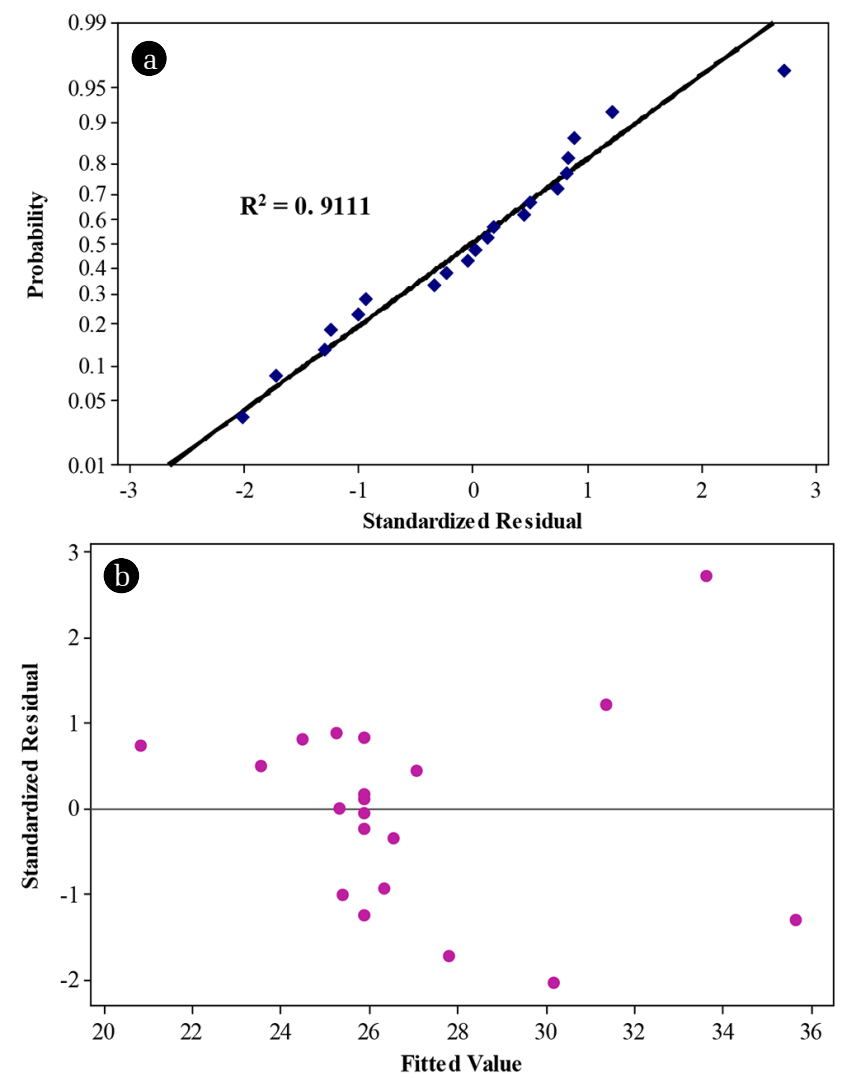

Fig. 1. Normal probability plot and Residual vs Fits plot for banana peels biochar response (\% wt.).

as a way of eradicating the initial oxygen enabling an inert atmosphere condition [6]. Consequently, the system was first heated up to $100^{\circ} \mathrm{C}$ to drive away the air originally in the reactor. Successively, the reactor with the samples was heated to the desired temperatures of $350-550^{\circ} \mathrm{C}$ while the residence time being varied between 45-90 min according to the experimental design run randomization [9].

The final product yields were weighed by analytical balance and expressed as $\mathrm{Y}_{\text {vinegar }}, \mathrm{Y}_{\mathrm{tar}}, \mathrm{Y}_{\text {biochar }}$, and $\mathrm{Y}_{\text {non condensable gases [6]. }}$. They were determined on a wet mass basis (wb, wt.\%) of the initial dried biomass feed, $\mathrm{m}_{\text {biomass, }}$ as illustrated by the Eq. (1)-(3) [28]. However, bio-oil yield was taken as the total liquid products (vinegar and tar) collected from the initial biomass feed content [29]. The vinegar and tar compounds were characterized via gas chromatography (GC) and physicochemical properties analyses while for biochar the calorific values were examined [30].

$$
\begin{gathered}
Y_{\text {vinegar }}(w b, w t . \%)=\left(\frac{M_{2}-M_{1}}{M_{o}}\right) \times 100 \\
Y_{\text {tar }}(w b, w t . \%)=\left(\frac{M_{3}-M_{1}}{M_{o}}\right) \times 100 \\
Y_{\text {biochar }}(w b, w t . \%)=\left(\frac{M_{R 1}-M_{R o}}{M_{o}}\right) \times 100
\end{gathered}
$$

Where: $\mathrm{M}_{0}=$ weight of biomass feed, $\mathrm{M}_{1}=$ Weight of empty measuring cylinder, $\mathrm{M}_{2}=$ Weight of measuring cylinder with vinegar, $\mathrm{M}_{3}=$ Weight of measuring cylinder with tar, $\mathrm{M}_{\mathrm{R} 0}=$ weight of empty reactor, and $\mathrm{M}_{\mathrm{R} 1}=$ Weight of reactor with biochar while the non-condensable gas (NCG) yields were determined from the difference [29].

The percentage conversion of the biomass feedstock to liquid and gaseous products was determined by subtracting the total biochar yield from $100 \%$ [28]. Once one test was done and yields collected, the experiment was repeated for a total of 20 runs according to the experimental design as depicted in Table S1.

\subsection{Experimental Design}

RSM was used to optimize the slow pyrolysis of banana wastes for optimum yield of vinegar, tar and biochar. It ensured that the correlation between the responses (vinegar, tar, biochar and NCG) and the quantitative experimental variables (heating temperature, sample mass and residence time) were examined [31]. The major aim of using RSM was to get the factor combinations that would yield optimal response and also portray curvatures in the response surfaces [32]. Minitab 16 software (Version 16.1.1.0) provided two response surface designs: CCDs and Box-Behnken designs, of which CCD was the most suitable [21]. CCD was able to fit first-order (linear) and second-degree models with the aid of the axial and center points. Similarly, design properties as orthogonality, curvature and rotatability were estimated through CCD [32].

A CCD composed of a two-level factorial design $\left(2^{\mathrm{n}}\right)$; $\mathrm{m}$ center point experiments $(0,0)$ that are augmented with a group of ax$\mathrm{ial} / \mathrm{star}$ points (2.n) was employed. The span from factorial point design space to the center point was taken as either +1 or -1 and from the center to the star points as alpha $|\alpha|>1$ [33]. The total number of experiments, N, was calculated by Eq. (4) [26], where $\mathrm{n}$ is the numbers of factors and $\mathrm{m}$ center points. Consequently, a series of 20 experimental runs, 8 factorial (cube) points, 6 axial points and 6 center points $(\mathrm{m}=6)$ replicate based on 3 factors (variables) and 3 base block experiments were performed. The number of axial/star points in a CCD was twice the total number of the design factors and they denoted the extreme values (low or high) for each design factor. Thus, the CCD was experimented in multiple blocks to create orthogonality within the blocks, enabling factors and block effects to be estimated solely while minimizing the variation in the regression coefficients [32].

$$
N=2^{n}+2 n+m=2^{3}+2(3)+6=20
$$

Therefore, the banana biomass wastes were pyrolyzed over a temperature range of $350-550^{\circ} \mathrm{C}$, sample mass in the range of 200-800 g and residence time of between 45-90 min to yield wood vinegar, tar, biochar and NCG. The coded and actual levels, as well as the experimental variables, are outlined in Table 2.

Eventually, a CCD with the full factorial was developed using the Minitab 16 software. Each factor was varied over five levels: the high level $(+1)$, the low level (-1), the center points (coded level 0 ) and two outer points $( \pm \alpha)$ corresponding to a value of \pm 1.633 $[33,34]$. Table S1 summarizes the coded and experimental variables 
Table 2. Coded and Experimental Variables for CCD

\begin{tabular}{clccccc}
\hline \multirow{2}{*}{ Coded variable } & Experimental variable & \multicolumn{3}{c}{ Coded level and actual level } \\
\cline { 3 - 6 } & & $\boldsymbol{- \alpha}$ & $\mathbf{- 1}$ & $\mathbf{0}$ & $\mathbf{+ 1}$ & $\mathbf{+ \alpha}$ \\
\hline A & Set-point temperature $\left({ }^{\circ} \mathrm{C}\right)$ & 286.7 & 350 & 450 & 550 & 613.3 \\
B & Sample mass (g) & 10.1 & 200 & 500 & 800 & 989.9 \\
C & Residence time (min) & 30.75 & 45 & 67.5 & 90 & 104.24 \\
\hline
\end{tabular}

Table 3. CCD Run Order and Response Yields for Banana Peels

\begin{tabular}{|c|c|c|c|c|c|c|c|c|c|}
\hline $\begin{array}{l}\text { Std } \\
\text { order }\end{array}$ & $\begin{array}{l}\text { Run } \\
\text { order }\end{array}$ & $\begin{array}{c}\text { Temp. } \\
\left({ }^{\circ} \mathrm{C}\right)\end{array}$ & $\begin{array}{c}\text { Sample mass } \\
\text { (g) }\end{array}$ & $\begin{array}{l}\text { Res. time } \\
\text { (min) }\end{array}$ & $\begin{array}{l}\text { Vinegar } \\
\text { (\% wt.) }\end{array}$ & $\begin{array}{c}\text { Tar } \\
\text { (\% wt.) }\end{array}$ & $\begin{array}{l}\text { Biochar } \\
\text { (\% wt.) }\end{array}$ & $\begin{array}{c}\text { NCG } \\
\text { (\% wt.) }\end{array}$ & $\begin{array}{c}\text { Total } \\
(\%)\end{array}$ \\
\hline 10 & 1 & 550.00 & 800.00 & 90.00 & 21.36 & 27.39 & 25.34 & 25.93 & 100.01 \\
\hline 11 & 2 & 450.00 & 500.00 & 67.50 & 7.68 & 30.74 & 25.82 & 35.76 & 100.00 \\
\hline 7 & 3 & 550.00 & 200.00 & 45.00 & 29.65 & 34.75 & 24.15 & 12.80 & 101.35 \\
\hline 12 & 4 & 450.00 & 500.00 & 67.50 & 4.22 & 30.92 & 24.54 & 40.32 & 100.00 \\
\hline 9 & 5 & 350.00 & 200.00 & 90.00 & 8.80 & 37.62 & 28.80 & 25.85 & 101.07 \\
\hline 8 & 6 & 350.00 & 800.00 & 45.00 & 24.44 & 18.15 & 26.31 & 31.10 & 100.00 \\
\hline 20 & 7 & 450.00 & 500.00 & 67.50 & 3.84 & 24.58 & 25.62 & 45.84 & 99.88 \\
\hline 18 & 8 & 450.00 & 500.00 & 104.24 & 11.22 & 24.90 & 25.10 & 38.80 & 100.02 \\
\hline 13 & 9 & 286.70 & 500.00 & 67.50 & 7.02 & 31.72 & 32.26 & 29.02 & 100.02 \\
\hline 15 & 10 & 450.00 & 10.10 & 67.50 & 18.81 & 25.74 & 35.64 & 20.79 & 100.99 \\
\hline 14 & 11 & 613.30 & 500.00 & 67.50 & 5.82 & 26.10 & 23.92 & 44.16 & 100.00 \\
\hline 16 & 12 & 450.00 & 989.90 & 67.50 & 29.30 & 10.87 & 24.65 & 35.16 & 99.97 \\
\hline 19 & 13 & 450.00 & 500.00 & 67.50 & 8.94 & 21.94 & 26.76 & 42.34 & 99.98 \\
\hline 17 & 14 & 450.00 & 500.00 & 30.76 & 24.66 & 24.36 & 25.92 & 25.06 & 100.00 \\
\hline 5 & 15 & 450.00 & 500.00 & 67.50 & 9.02 & 26.36 & 26.06 & 38.56 & 100.00 \\
\hline 3 & 16 & 550.00 & 200.00 & 90.00 & 7.00 & 28.35 & 25.70 & 38.9 & 99.95 \\
\hline 4 & 17 & 350.00 & 800.00 & 90.00 & 23.53 & 13.86 & 27.36 & 35.25 & 100.00 \\
\hline 2 & 18 & 550.00 & 800.00 & 45.00 & 22.53 & 17.33 & 21.30 & 38.84 & 99.99 \\
\hline 6 & 19 & 450.00 & 500.00 & 67.50 & 20.14 & 25.04 & 26.00 & 28.84 & 100.02 \\
\hline 1 & 20 & 350.00 & 200.00 & 45.00 & 15.65 & 37.55 & 34.75 & 12.05 & 100.00 \\
\hline
\end{tabular}

for CCD. Similarly, the response data set for the banana peels wastes experimented as recorded by Minitab is illustrated in Table 3.

\subsection{Statistical and Optimization Analysis}

All statistical analysis including regression modeling, ANOVA and the response surfaces and contour plots were performed and investigated using Minitab 16.1.1.0 software [21]. Significant differences between the treatments were statistically taken at the level of $p \leq 0.05$ [35]. The optimum conditions for the three variables, heating temperature (A), sample mass (B) and residence time (C) was obtained using data from the statistical analysis. Similarly, Minitab software was used to fit the equations developed and to prepare the response surfaces and contour plots.

\section{Results and Discussion}

\subsection{Experimental Results}

The experimental mass balance accuracy between the mass fed and product yields for banana peels waste samples were approx- imately $99.95 \%$ despite minimal outliers. The percentage product yields for the 20 runs of the banana peels biomass samples are illustrated in Table 3. The highest yields of peels vinegar, tar and biochar were $29.30 \%, 37.62 \%$, and $35.64 \%$, respectively. The accumulated mass percentages for the banana peels yields are outlined in Fig. S2. The biochar yield (25.87\%) was generally high compared to vinegar (16.62\%) and tar (23.34\%) for all the runs and this was justified by the fact that the experiment employed slow pyrolysis system [13]. Contrariwise, the values of NCG and wastewater was quantified arbitrarily by getting the difference between the mass of biomass fed and total mass yields of vinegar, tar and biochar. Remarkably, the energy conversion efficiency of the pyrolysis system was very high. For every $10 \mathrm{~kg}$ of banana peels wastes fed into the reactor $1.6 \mathrm{~kg}$ of vinegar, $2.3 \mathrm{~kg}$ of tar, $2.6 \mathrm{~kg}$ of biochar and $3.7 \mathrm{~kg}$ of NCG and wastewater was generated from banana peels wastes.

\subsection{Statistical and Regression Analysis of Vinegar, Tar and Char Models}

Statistical analysis was done in this study to investigate the relationship that exists between the factors (temperature, mass fed 

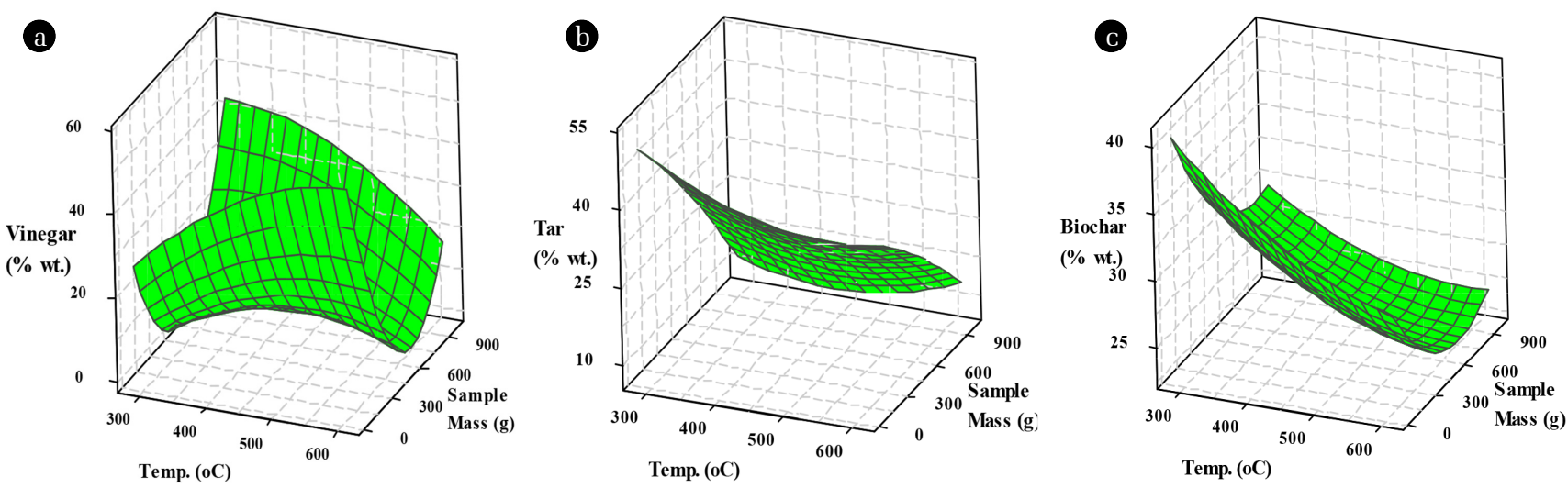

Fig. 2. Surface plots of banana peels vinegar, tar and biochar yield (\%) versus sample mass (g) and temperature $\left({ }^{\circ} \mathrm{C}\right)$ residence time (min).

Table 4. Reduced Regression Model Coefficients for Banana Peels

\begin{tabular}{|c|c|c|c|c|c|c|}
\hline Parameter & \multicolumn{2}{|c|}{ Vinegar response } & \multicolumn{2}{|c|}{ Tar response } & \multicolumn{2}{|c|}{ Biochar response } \\
\hline $\mathrm{R}^{2}$ & \multicolumn{2}{|c|}{$84.35 \%$} & \multicolumn{2}{|c|}{$83.90 \%$} & \multicolumn{2}{|c|}{$94.13 \%$} \\
\hline Adj. $R^{2}$ & \multicolumn{2}{|c|}{$70.27 \%$} & \multicolumn{2}{|c|}{$69.40 \%$} & \multicolumn{2}{|c|}{$88.84 \%$} \\
\hline Error term & \multicolumn{2}{|c|}{4.75271} & \multicolumn{2}{|c|}{5.51408} & \multicolumn{2}{|c|}{1.17305} \\
\hline Term & Coefficient & $p$-value & Coefficient & $p$-value & Coefficient & $p$-value \\
\hline Regression & - & 0.005 & - & 0.006 & - & $<0.001$ \\
\hline Constant & 8.8450 & 0.001 & 26.4165 & $<0.001$ & 25.8902 & $<0.001$ \\
\hline A & 0.4624 & 0.730 & -1.4308 & 0.366 & -2.5767 & $<0.001$ \\
\hline B & 3.5903 & 0.020 & -10.2085 & $<0.001$ & -2.3281 & $<0.001$ \\
\hline $\mathrm{C}$ & -4.0142 & 0.012 & -1.0607 & 0.498 & -0.0489 & 0.906 \\
\hline $\mathrm{A}^{2}$ & -0.4763 & 0.723 & 1.5430 & 0.333 & 0.5205 & 0.226 \\
\hline $\mathrm{B}^{2}$ & 6.1364 & 0.001 & -0.7627 & 0.626 & 1.2916 & 0.009 \\
\hline $\mathrm{C}^{2}$ & 3.8437 & 0.015 & -0.0620 & 0.968 & -0.4470 & 0.294 \\
\hline $\mathrm{AB}$ & -2.0344 & 0.254 & 1.2875 & 0.524 & 0.8328 & 0.139 \\
\hline AC & -2.0063 & 0.260 & -3.4812 & 0.104 & 1.3109 & 0.030 \\
\hline $\mathrm{BC}$ & 3.4281 & 0.069 & 0.1969 & 0.922 & 1.1859 & 0.045 \\
\hline Lack-of-fit & - & 0.901 & - & 0.087 & - & 0.025 \\
\hline
\end{tabular}

At $95 \%$ confidence $(\alpha=0.05)$.

${ }^{*} \mathrm{~A}=$ Temp. $\left({ }^{\circ} \mathrm{C}\right), \mathrm{B}=$ Sample mass $(\mathrm{g})$ and $\mathrm{C}=$ Residence time (min)

and the residence time) and the responses (vinegar, tar, biochar and NCG yields). The statistical significance of the factors was examined using probability $(p)$ values and $F$-tests at $95 \%$ confidence level generating regression coefficients and ANOVA for the quadratic model of the response surfaces. The larger the $F$-value the more significant the variable while $p$-values less than 0.05 indicated a significant model term. Again, the relatively smaller $p$-values of the squared and the interactions terms denoted a firm possibility of a response surface curvature. Both the ANOVA and regression analysis compared the linear, quadratic and interaction terms and tested their $p$-values for significance [36].

Regression analysis is a typical empirical approach of fitting models [34]. Thus the regression analysis of vinegar, tar, and biochar was conducted using coded values as was illustrated in the experimental design (Table S1). The Minitab 16 software generated fitted models, their coefficients, the $R^{2}$ values as well as the $F$ and $p$ values from which the statistical significance of the experimental factors was investigated. Table 4 outline the estimated regression coefficients and ANOVA for reduced regression models for banana peels vinegar, tar and biochar yields.

The linear, quadratic and interaction of all the factors, banana peels regression and ANOVA models indicated well fit higher-order full quadratic models. This was true due to the higher $\mathrm{R}^{2}$ values (vinegar $=0.84, \operatorname{tar}=0.80$ and biochar $=0.91$ ) and the smaller error terms (vinegar, $S=4.75$, tar, $S=4.38$ and biochar, $S=1.47$ ). Thus the models sufficiently fitted the data and there was an immense reduction of the factors variability. Furthermore, the high $F$-values and the low $p$-values for the models lack of fit indicated no significant lack of fit for banana peels responses and proved that the models were statistically significant 
[26]. Therefore, sample mass (B) $p=0.020$, residence time (C) $p=0.012$ and the quadratic terms of sample mass $\left(\mathrm{B}^{2}\right) p=<$ 0.001 and residence time $\left(C^{2}\right) p=0.015$, had a significant effects on banana peels vinegar yield. Equally, sample mass (B) $p=$ $<0.001$ also had significant effects on banana peels tar response. Moreover, temperature (A) $p=<0.001$, sample mass (B) $p=$ $<0.001$ and residence time (C) $p=<0.001$, quadratic term for sample mass $\left(\mathrm{B}^{2}\right) p=0.009$ as well as the interactions of temperature and residence time (AC) $p=0.030$ and sample mass and residence time (BC) terms $p=0.045$, also had significant impact to the banana peels biochar yields. Conversely, the quadratic terms of temperature $\left(\mathrm{A}^{2}\right) p=0.723$, quadratic terms for residence time $\left(\mathrm{C}^{2}\right) p=0.991$ and the interaction of terms between temperature and sample mass $(\mathrm{AB}) p=0.139$, showed no significant influence on the yields of banana peels vinegar, tar, and biochar, respectively.

To investigate further yields of the banana vinegar, tar and biochar, model coefficients were generated using the uncoded terms. All the coefficients of the model terms were evaluated solely using CCD as the experimental design in Minitab 16 software. According to Brown and Brown [26], a positive term in a model indicates an increase in the response with the increase of the variable while a negative term indicates a decrease in the response yield with the increase of the variable. Importantly, the models took into considerations the three main factors of the experiment design, their quadratic and interaction effects and significance. The final models from coefficients of the uncoded terms of banana peel vinegar, tar and biochar as generated by Minitab 16 software are given in Eq. (5)-(7). The yields were expressed as percentage weights wet basis (wb).

$$
\begin{aligned}
& \mathbf{Y}_{\text {vinegar }}= 29.62+0.14 \mathrm{~A}-0.06 \mathrm{~B}-1.06 \mathrm{C}- \\
& 4.76 \mathrm{E}-05 \mathrm{~A}^{2}+6.8276 \mathrm{E}-05 \mathrm{~B}^{2}+0.0076 \mathrm{C}^{2}- \\
& 6.78 \mathrm{E}-05 \mathrm{AB}-8.92 \mathrm{E}-04 \mathrm{BC}+0.00051 \mathrm{AC} \\
& \mathbf{Y}_{\text {tar }}=110.39-0.233 \mathrm{~A}-0.057 \mathrm{~B}-0.312 \mathrm{C}+ \\
& 0.00016 \mathrm{~A}^{2}-6.19 \mathrm{E}-05 \mathrm{~B}^{2}+2.742 \mathrm{E}-05 \mathrm{C}^{2}+ \\
& 0.0001 \mathrm{AB}+0.00044 \mathrm{BC}+0.00022 \mathrm{AC} \\
& \\
& \mathbf{Y}_{\text {biochar }}= 81.49-0.126 \mathrm{~A}-0.046 \mathrm{~B}-0.223 \mathrm{C}+ \\
& 5.20 \mathrm{E}-05 \mathrm{~A}^{2}+1.44 \mathrm{E}-05 \mathrm{~B}^{2}-8.83 \mathrm{E}-04 \mathrm{C}^{2}+ \\
& 2.78 \mathrm{E}-05 \mathrm{AB}+0.00058 \mathrm{BC}+0.0018 \mathrm{AC}
\end{aligned}
$$

Where: $\mathbf{Y}$ is the response yield expressed in percentage weight of the fed biomass weight, while A, B and C are the coded terms representing the three variables of the experiment, that is, temperature (A), sample mass (B) and residence time (C).

A positive sign before a term in the model signifies a mutually beneficial effect, while a negative sign indicates an incompatible effect [34]. Using the regression models generated, predicted responses for new design points were generated for banana peels vinegar, tar, biochar and NCG responses. Table S2 illustrates the experimental and predicted responses for the banana peels samples as generated using Minitab 16 software's regression models.

The normal probability plot and residual versus fits plots are further investigators of the goodness of model fit. Standardized residuals and normal probability plots generated by Minitab 16 software at a 95\% confidence interval were employed in this study as illustrated in Fig. 1. From the plots, it can be seen that the points on the plot were generally a straight line indicating normality in the distribution of the residuals. Similarly, from the residuals versus fits plots, there was a random pattern of residuals on either side of zero (0) with very few outliers for all the samples. This strongly indicated that the error was randomized and that predictor model for the pyrolysis responses had the goodness of fit and was efficient in analyzing the effects of input variables on the response yields [36].

\subsection{Factor Variations and Effects on Vinegar and Tar Yield Models}

The contour and response surface plots further outlined the interaction that exists between the factors of the slow pyrolysis process. Majorly, 3 D-surface and contour plots aided in the categorization of the surface projections for the variables in consideration. Similarly, they expressed the usefulness of each variable on the amount of targeted response [36]. The relationship between the heating temperature and the sample mass fed while holding residence time constant were examined as well as the interaction between heating temperature and residence time while holding the sample mass constant. From Fig. 2 it is noted that an increase in temperature at lower mass fed for banana peels yields high vinegar content and also that increasing the sample mass at lower temperatures leads to the same results. The peels tar yields were high at low temperatures of $300-450^{\circ} \mathrm{C}$ and low sample mass $100-400$ g (Fig. 3).
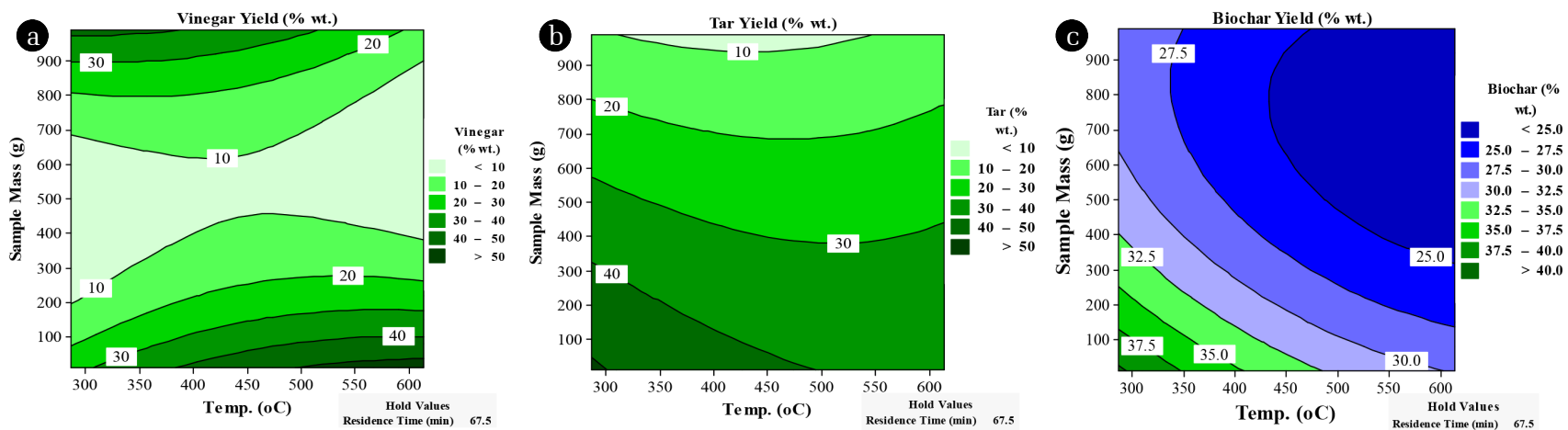

Fig. 3. Contour plots of banana peels vinegar, tar and biochar yield $(\%)$ versus sample mass $(\mathrm{g})$ and temperature $\left({ }^{\circ} \mathrm{C}\right)$ residence time $(\mathrm{min})$. 
Table 5. Response Optimization Parameters and Predicted Response for Banana Peels Vinegar, Tar and Biochar

\begin{tabular}{|c|c|c|c|c|c|c|c|}
\hline $\begin{array}{l}\text { Optimized } \\
\text { sample }\end{array}$ & $\begin{array}{l}\text { Variable } \\
\text { (\% wt.) }\end{array}$ & Goal & $\begin{array}{l}\text { Predicted } \\
\text { response }\end{array}$ & Desirability & $\begin{array}{c}\text { Overall } \\
\text { desirability }\end{array}$ & $\begin{array}{c}\text { Global } \\
\text { solution }\end{array}$ & $\begin{array}{c}\text { Confirmation } \\
\text { response }\end{array}$ \\
\hline \multirow{3}{*}{$\begin{array}{l}\text { Peels } \\
\text { Vinegar }\end{array}$} & Vinegar & Maximize & 48.91 & 1.0000 & \multirow{3}{*}{0.990523} & \multirow{3}{*}{$\begin{array}{c}362.6^{\circ} \mathrm{C} \\
989.9 \mathrm{~g} \\
104.2 \mathrm{~min}\end{array}$} & $48.01 \pm 0.53$ \\
\hline & Tar & Minimize & 9.68 & 1.0000 & & & $9.90 \pm 0.45$ \\
\hline & Biochar & Target & 27.01 & 0.7986 & & & $26.32 \pm 1.13$ \\
\hline \multirow{3}{*}{$\begin{array}{l}\text { Peels } \\
\text { Tar }\end{array}$} & Vinegar & Minimize & 15.00 & 1.0000 & \multirow{3}{*}{1.000000} & \multirow{3}{*}{$\begin{array}{c}286.7^{\circ} \mathrm{C} \\
171.6 \mathrm{~g} \\
104.0 \mathrm{~min}\end{array}$} & $15.60 \pm 0.42$ \\
\hline & Tar & Maximize & 42.41 & 1.0000 & & & $40.92 \pm 1.05$ \\
\hline & Biochar & Target & 30.00 & 1.0000 & & & $27.50 \pm 1.77$ \\
\hline \multirow{3}{*}{$\begin{array}{l}\text { Peels } \\
\text { Biochar }\end{array}$} & Vinegar & Target & 15.00 & 1.0000 & \multirow{3}{*}{0.850495} & \multirow{3}{*}{$\begin{array}{c}585.9^{\circ} \mathrm{C} \\
989.9 \mathrm{~g} \\
104.2 \mathrm{~min}\end{array}$} & $18.13 \pm 2.21$ \\
\hline & Tar & Minimize & 2.38 & 1.0000 & & & $3.62 \pm 0.88$ \\
\hline & Biochar & Maximize & 29.23 & 0.6152 & & & $30.10 \pm 0.62$ \\
\hline
\end{tabular}

\subsection{Factor Variations and Effects on Char Yield Model}

The highest biochar yields form banana peels were experienced at low temperatures $\left(300-450^{\circ} \mathrm{C}\right)$ and low sample mass $(100-400$ g) (Fig. 3). Critical further comparisons showed that high heating temperatures reduced the yield of biochar while favoring the yields of tar and vinegar for all the samples. Therefore, heating temperature and amount of biomass fed had a significant influence on the yields of the three responses compared to residence time.

\subsection{Optimization Analysis}

A global solution of the optimum variables settings that would yield the maximum response, their combined desirability and a prediction of response was generated from Minitab 16 software. Table 5 outlines the optimal global solutions of the three banana biomass samples indicating different responses from the targeted variable optimization. Using the global solution variables, confirmatory pyrolysis experiments were conducted and the new responses recorded (Table 5). For instance, the generated optimal solutions from the Minitab 16 software indicated the maximum peels vinegar yield $48.91 \%$ to occur at a temperature of $362.6^{\circ} \mathrm{C}$, sample mass of $989.9 \mathrm{~g}$ and residence time of $104.2 \mathrm{~min}$. This was established from the confirmation response yields which showed the optimal vinegar yield for peels at the global solution variables as $48.01 \%$. This was true for all the responses (vinegar, tar, and biochar) as in Table 5. Therefore, these results proved that predicted values from the optimal global solutions are good and viable models for optimization as supported by small the error margins (lower standard deviations) between the predicted and the realized values [7].

\section{Conclusions}

The design and the experimental systems of the reactor were suitable for the slow pyrolysis of banana peels wastes. The percentage proportions of the responses were averagely high with biochar (25.87\%) being the highest followed by tar (23.34\%) and vinegar (16.62\%). The pyrolysis batch reactor can be possibly scaled-up and used in commercial industries for various pyrolysis work utilizing different types of biomass wastes. The CCD was very successful in examining the correlation between the experimental variables (heating temperature, sample mass fed and residence time) and the response yield (vinegar, tar, biochar, and NCG). Statistical regression models generated predicted adequately the yields of vinegar, tar, and biochar for banana peel biomass. The optimization of the response yields from banana wastes samples was achieved by minimizing one response and setting the other at the target. Therefore, the slow pyrolysis optimization of banana peels wastes for vinegar, tar and biochar yields laid a manifold foundation for similar work in future.

\section{Acknowledgments}

Much appreciation to METEGA project and RUFORUM for financing this research and University of Kentucky Appropriate Technology Sustainability Research group (UKATS) for the fabrication of the rocket stove and batch reactor.

\section{References}

1. Acikgoz C, Kockar OM. Characterization of slow pyrolysis oil obtained from linseed (Linum usitatissimum L.). J. Anal. Appl. Pyrolysis 2009;85:151-154.

2. Önal EP, Uzun BB, Pütün AE. Steam pyrolysis of an industrial waste for bio-oil production. Fuel Process. Technol. 2011;92: 879-885.

3. Wu X, Markham J, Sun XS, Wang D. Optimizing catalytic fast pyrolysis of biomass for hydrocarbon yield. Am. Soc. Agric. Biol. Eng. 2012;55:1879-1885.

4. Çepelioğullar Ö, Pütün AE. Products characterization study of a slow pyrolysis of biomass-plastic mixtures in a fixed-bed reactor. J. Anal. Appl. Pyrolysis 2014;110:363-374.

5. Volpe M, Panno D, Volpe R, Messineo A. Upgrade of citrus waste as a biofuel via slow pyrolysis. J. Anal. Appl. Pyrolysis 2015;115:66-76.

6. Soetardji JP, Widjaja C, Djojorahardjo Y, Soetaredjo FE, Ismadji S. Bio-oil from jackfruit peel waste. Procedia Chem. 2014;9: 
158-164.

7. Fan Y, Cai Y, Li X, et al. Rape straw as a source of bio-oil via vacuum pyrolysis: Optimization of bio-oil yield using orthogonal design method and characterization of bio-oil. J. Anal. Appl. Pyrolysis 2014;106:63-70.

8. Brennan L, Owende P. Biofuels from microalgae - A review of technologies for production, processing, and extractions of biofuels and co-products. Renew. Sustain. Energ. Rev. 2010;14:557-577.

9. Jourabchi SA, Gan S, Ng HK. Pyrolysis of Jatropha curcas pressed cake for bio-oil production in a fixed-bed system. Energ. Convers. Manage. 2014;78:518-526.

10. Demirbas A. Biofuels sources, biofuel policy, biofuel economy and global biofuel projections. Energ. Convers. Manage. 2008;49:2106-2116.

11. Cantrell KB, Hunt PG, Uchimiya M, Novak JM, Ro KS. Impact of pyrolysis temperature and manure source on physicochemical characteristics of biochar. Bioresour. Technol. 2012;107:419-428.

12. Brewer CE, Schmidt-Rohr K, Satrio JA, Brown RC. Characterization of biochar from fast pyrolysis and gasification systems. Environ. Prog. Sustain. Energ. 2009;28:386-396.

13. Tripathi M, Sahu JN, Ganesan P. Effect of process parameters on production of biochar from biomass waste through pyrolysis: A review. Renew. Sustain. Energ. Rev. 2016;55:467-481.

14. Chang YM, Tsai WT, Li MH. Chemical characterization of char derived from slow pyrolysis of microalgal residue. J. Anal. Appl. Pyrolysis 2015;111:88-93.

15. Doumer ME, Arizaga GGC, da Silva DA, et al. Slow pyrolysis of different Brazilian waste biomasses as sources of soil conditioners and energy, and for environmental protection. J. Anal. Appl. Pyrolysis 2015;113:434-443.

16. Carrier M, Hugo T, Gorgens J, Knoetze H. Comparison of slow and vacuum pyrolysis of sugar cane bagasse. J. Anal. Appl. Pyrolysis 2011;90:18-26.

17. Cordella M, Berrueco C, Santarelli F, Paterson N, Kandiyoti R, Millan M. Yields and ageing of the liquids obtained by slow pyrolysis of sorghum, switchgrass and corn stalks. J. Anal. Appl. Pyrolysis 2013;104:316-324.

18. Omulo G, Banadda N, Kiggundu N. Harnessing of banana ripening process for banana juice extraction in Uganda. Afr. J. Food Sci. Technol. 2015;6:108-117.

19. Fernandes ERK, Marangoni C, Souza O, Sellin N. Thermochemical characterization of banana leaves as a potential energy source. Energ. Convers. Manage. 2013;75:603-608.

20. Kabenge I, Omulo G, Banadda N, Seay J, Zziwa A, Kiggundu $\mathrm{N}$. Characterization of banana peels wastes as potential slow pyrolysis feedstock. J. Sustain. Dev. 2018;11:14.

21. Minitab. Minitab incorperated for Windows User. Language Pack - English: 16.1.1.0, Licensing: 16.1.1.1 and Core: 16.1.1.0.
US office: Canada and Mexico; 2010.

22. Van-Soest PJ, Wine RH. Determination of lignin and cellulose in acid-detergent fiber with permanganate. J. Assoc. Off. Anal. Chem. 1968;51:780-785.

23. Pérez-Hidalgo M, Guerra-Hernández E, García-Villanova B. Determination of insoluble dietary fiber compounds: Cellulose, hemicellulose and lignin in legumes. Ars Pharm. 1997;38:357-364.

24. Smets K, Roukaerts A, Czech J, et al. Slow catalytic pyrolysis of rapeseed cake: Product yield and characterization of the pyrolysis liquid. Biomass Bioenerg. 2013;57:180-190.

25. Sait HH, Hussain A, Salema AA, Ani FN. Pyrolysis and combustion kinetics of date palm biomass using thermogravimetric analysis. Bioresour. Technol. 2012;118:382-389.

26. Brown JN, Brown RC. Process optimization of an auger pyrolyzer with heat carrier using response surface methodology. Bioresour. Technol. 2012;103:405-414.

27. Joshi CA, Seay JR. An appropriate technology based solution to convert waste plastic into fuel oil in underdeveloped regions. J. Sustain. Dev. 2016;9:133.

28. Biswas B, Singh R, Kumar J, Khan AA, Krishna BB, Bhaskar T. Slow pyrolysis of prot, alkali and dealkaline lignins for production of chemicals. Bioresour. Technol. 2016;213:319-326.

29. Moore A, Park S, Segura C, Carrier M. Fast pyrolysis of lignin-coated radiata pine. J. Anal. Appl. Pyrolysis 2015;115: 203-213.

30. Hwang H, Oh S, Choi IG, Choi JW. Catalytic effects of magnesium on the characteristics of fast pyrolysis products - Bio-oil, bio-char, and non-condensed pyrolytic gas fractions. J. Anal. Appl. Pyrolysis 2015;113:27-34.

31. Myers RH, Montgomery DC. Response surface methodology: Process and product optimization using designed experiments. New York: Wiley; 1995.

32. Montgomery DC. Design and analysis of experiments. 6th ed. John Wiley \& Sons; 2004.

33. Januszkiewicz J, Sabik H, Azarnia S, Lee B. Optimization of headspace solid-phase microextraction for the analysis of specific flavors in enzyme modified and natural Cheddar cheese using factorial design and response surface methodology. J. Chromatogr. A 2008;1195:16-24.

34. Azim Jamaluddin M, Ismail K, Ishak MAM, et al. Microwave-assisted pyrolysis of palm kernel shell: Optimization using response surface methodology (RSM). Renew. Energ. 2013;55: 357-365.

35. Wang Y, Yin R, Liu R. Characterization of biochar from fast pyrolysis and its effect on chemical properties of the tea garden soil. J. Anal. Appl. Pyrolysis 2014;110:375-381.

36. Kılıç M, Pütün E, Pütün AE. Optimization of Euphorbia rigida fast pyrolysis conditions by using response surface methodology. J. Anal. Appl. Pyrolysis 2014;110:163-171. 